\title{
Oral health behaviour in migrant and non- migrant adults in Germany: the utilization of regular dental check-ups
}

\author{
Fabian Erdsiek, Dorothee Waury and Patrick Brzoska*
}

\begin{abstract}
Background: Migrants in many European countries including Germany tend to utilize preventive measures less frequently than the majority population. Little is known about the dental health of migrants as well as about their oral health behaviour, particularly in the adult population. The aim of this study was to examine differences in the uptake of annual dental check-ups in adult migrants and non-migrants in Germany.

Methods: We used data from the cross-sectional survey 'German Health Update 2010' conducted by the Robert Koch Institute $(n=22,050)$. Data from 21,741 German-speaking respondents with information on the use of dental check-ups was available, of which 3404 (15.7\%) were migrants. Multiple logistic regression models were applied to adjust for demographic and socioeconomic confounders, including the place of residence as well as type of health insurance.

Results: Migrants were generally younger, had a lower socioeconomic status and showed a lower utilization of dental check-ups. The unadjusted odds ratio (OR) for utilization was $0.67(95 \%-\mathrm{Cl}=0.61-0.73)$. After adjusting for demographic and socioeconomic confounders the chance only increased slightly (adjusted $\mathrm{OR}=0.71 ; 95 \%-\mathrm{Cl}=0.65-0.77$ ).

Conclusions: The analysis shows that migration status is associated with a reduced chance of attending dental checkups, independently of demographic and socioeconomic factors. The influence of other factors, such as type of health insurance and place of residence had also no influence on the association. Migrants are exposed to different barriers in the health care system, comprising the patient, provider and system level. Further studies need to examine the relevant barriers for the uptake of preventive dental services in order to devise appropriate migrant- sensitive measures of dental prevention.
\end{abstract}

Keywords: Migrants, Oral health, Dental check-ups, Prevention

\section{Background}

Adequate access and utilization of the health system by migrants has become a subject of growing interest in health research given that migrants constitute a large and growing share of the population in many European and other countries. In Germany, migrants account for more than $20 \%$ of the population, subsuming both foreign nationals as well as Germans with a migrant background [1]. Migrants differ from the majority populations of the respective host countries in a variety of health aspects comprising the prevalence of certain

\footnotetext{
* Correspondence: patrick.brzoska@soziologie.tu-chemnitz.de Epidemiology Unit, Institute of Sociology, Faculty of Behavioral and Social Sciences, Chemnitz University of Technology, D-09107 Chemnitz, Germany
}

communicable and non-communicable diseases as well as the utilization of health care services $[2,3]$.

While the provision of health care services for regular migrants in Germany is nominally equal to that of nonmigrants and covered by the statutory or private health insurance (the situation is different for refugees and asylum seekers who only have limited access to health care [4]), the needs and expectations of migrant populations are often not adequately met in health care. This can negatively impact health care utilization and amongst others becomes evident in lower utilization of preventive health care services [3, 5-7]. In Germany, migrants have been found to use cancer screenings, vaccinations and 
rehabilitative services less often than the majority population [8-10].

In terms of oral health, studies addressing differences between migrants and non-migrants in Germany and other Western European countries, usually focus on oral and dental health of migrant children and/or specific migrant subgroups [11]. These studies mostly conclude that children with a migrant background are more likely to have a poorer oral health, manifesting predominantly in higher prevalence of caries [12-14]. The German Health Interview and Examination survey for Children and Adolescents (KiGGS) has, among other topics, examined demographic and socioeconomic determinants of dental hygiene and preventive behaviour in children and adolescents, concluding that children and adolescents with a migrant background more often did not reach recommended frequencies for tooth brushing and were less likely to use fluoride tablets $[15,16]$.

An important aspect of maintaining and promoting oral health is the utilization of regular dental check-ups at least once a year [17]. Studies from several countries show that migrants utilize dental check-ups less frequently than the respective autochthonous populations [18-21]. In Germany, research on the utilization of dental prevention measures among migrants is scarce, especially for adults. Small-scale studies have shown that migrant children were less likely to receive fissure sealings $[22,23]$ and orthodontic treatment [12] than non-migrant children. Results from the KiGGS survey have also shown that utilization of annual dental check-ups is lower among migrant children and adolescents than among their non-migrant counterparts in Germany, even after adjustment for age and socioeconomic status [16]. A recent descriptive analysis shows that the utilization of annual dental check-ups among adult migrants is less common for men and women of all groups of socioeconomic status [24]. The role of other confounding variables such as a private insurance and being married, which are also positively associated with regular dental visits [21, 25-27], was not accounted for. The aim of this paper is to examine whether migrant and non-migrant adults differ in the utilization of annual dental check-ups, taking into account socioeconomic and demographic aspects as well as additional contextual factors.

\section{Methods}

We did a secondary analysis using data from the crosssectional telephone survey 'German Health Update 2010', carried out between September 2009 and July 2010 by the Robert Koch Institute, a scientific institution of the German Federal Ministry of Health [28]. The study included information on health behaviour, health outcomes and utilization of health services. The sample was drawn from the population of adults in Germany aged 18 years or older who lived in a private household with a landline telephone. In order to determine the sample size, a power calculation to identify $50 \%$ prevalences with a $+/-5 \%$ error risk per cell (differentiating between regions, sexes and three age groups) was performed. Sampling was conducted using a modified random-digits approach, resulting in a sample of 12,483 female and 9567 male respondents [29]. Since only German-speaking adults were included, the sample is not representative for migrants with low or no proficiency of the German language. No other inclusion criteria were set.

The outcome of interest was the utilization of dental check-ups in the 12 months prior to the interview as a dichotomous variable. To determine migration status, we used a broader definition: individuals were defined as migrants if they had migrated to Germany themselves or if at least one of their parents had migrated to Germany, following the approach of other studies in the field [9]. To control for potentially confounding factors, we included several variables pertaining to demographic, socioeconomic and health aspects which often differ between migrants and non-migrants and which are associated with the utilization of health services [21, 24-27]. We included information on the respondents' sex and age (in 10-year age groups), as well as on their socioeconomic status (SES). In our analysis, we used SES as a categorical variable, distinguishing between high, middle and low status, using the measurement and categorization of Lampert et al. [30], which includes information on general and vocational educational, occupational status and net equivalent income. In terms of place of residence, information was included on whether respondents lived in West or East Germany and whether they lived in predominantly urban or more rural areas to take into account regional differences in availability of dental services. Cohabitation status was used with a distinction between respondents living together with a spouse/partner or not. Furthermore, we considered the type of health insurance (statutory as compared to private or other).

We calculated descriptive uni- and bivariate statistics to analyse the sample structure and to compare between groups according to migration status, using chi-squaretests and Wilcoxon-Mann-Whitney tests where appropriate. The association between migration status and use of dental check-ups was assessed by means of multivariable logistic regression modelling [31] adjusted for the aforementioned covariates as potential confounders. All analyses were done using Stata 13 [32].

\section{Results}

Due to missing information on the outcome variable or on one of the predictors, 309 individuals (1.4\%) were 
excluded from analysis. Of the 21,741 respondents remaining, $15.7 \%$ had a migrant background. Among the migrant participants, 2474 had either migrated themselves or had two parents who migrated to Germany, while 930 had not migrated to Germany but had one parent with migration experience. Differences between migrants and non-migrants were identified for some, but not all aspects (Table 1). The larger portion of the sample were female (56.7\%), with no significant difference between groups. Comparison of the age composition showed that migrants were significantly younger. Around 50\% were younger than 40 years, while this amounted to around $31 \%$ in the non-migrant group. Migrant respondents also more often had a lower socioeconomic status and were more often insured through statutory health insurance than non-migrants. In terms of place of residence, migrants lived significantly more often in West Germany and in urban areas. In both groups, the majority lived together with their spouse or a partner. With respect to the outcome it can be observed that utilization of dental prevention was overall lower among migrants (72.6\%) than nonmigrants $(79.8 \%)$, corresponding to a crude odds ratio (OR) of 0.67 .
When adjusting for the effects of sex, age, socioeconomic status and other confounders in the second model, the chance for utilization slightly increased, but was still considerably lower than for non-migrants (OR $=0.71$ ) (Table 2). In the adjusted model, the majority of the covariates were significantly associated with the outcome. Apart from the oldest group, all age groups had an increased chance of participation compared to the youngest group ranging from 18 to 29 years. While consistently higher than the reference group, the chance for using dental check-ups peaked for the age group from 40 to 49 years and decreased with higher age groups. Chances for utilization also increased consistently with higher socioeconomic status. Being female and living together with a partner or spouse was also found to enhance the chance of utilizing dental check-ups, while living in West Germany was associated with a reduced chance of utilization.

\section{Discussion}

The aim of this analysis was to compare the utilization of annual dental check-ups between migrants and nonmigrants in Germany. Using a national sample of adults, the study shows that utilization was lower among

Table 1 Description of the study sample by migrant status (German health update 2010 survey, $n=21,741$ )

\begin{tabular}{|c|c|c|c|c|}
\hline Variable & & $\begin{array}{l}\text { non-migrant } \\
n(\%)\end{array}$ & $\begin{array}{l}\text { migrant } \\
n(\%)\end{array}$ & $p$-value \\
\hline \multirow[t]{2}{*}{ Sex } & male & $7947(43.5)$ & $1447(42.6)$ & 0.33 \\
\hline & female & $10,317(56.5)$ & $1948(57.4)$ & \\
\hline \multirow[t]{7}{*}{ Age groups } & $18-29$ years & $2866(15.7)$ & $901(26.5)$ & $<0.01$ \\
\hline & $30-39$ years & $2720(14.9)$ & $784(23.1)$ & \\
\hline & $40-49$ years & $4211(23.0)$ & $691(20.4)$ & \\
\hline & $50-59$ years & $3407(18.7)$ & $444(13.1)$ & \\
\hline & $60-69$ years & $2799(15.3)$ & $361(10.6)$ & \\
\hline & 70-79 years & 1756 (9.6) & $172(5.1)$ & \\
\hline & $80+$ years & $505(2.8)$ & $42(1.2)$ & \\
\hline \multirow[t]{3}{*}{ Socioeconomic status } & high & $6278(34.4)$ & $965(28.4)$ & $<0.01$ \\
\hline & middle & $10,205(55.9)$ & $1827(53.8)$ & \\
\hline & low & $1781(9.8)$ & $603(17.8)$ & \\
\hline \multirow[t]{2}{*}{ Type of health insurance } & statutory & $14,939(81.8)$ & $3024(89.1)$ & $<0.01$ \\
\hline & private/other & $3325(18.2)$ & $371(10.9)$ & \\
\hline \multirow[t]{2}{*}{ Place of residence } & West Germany & $14,664(80.3)$ & $3034(89.4)$ & $<0.01$ \\
\hline & East Germany & $3600(19.7)$ & $361(10.6)$ & \\
\hline \multirow[t]{2}{*}{ Urban residence } & Yes & $12,501(68.4)$ & $2758(81.3)$ & $<0.01$ \\
\hline & No & 5763 (31.6) & $637(18.7)$ & \\
\hline \multirow[t]{2}{*}{ Living together with spouse/partner } & Yes & $11,373(62.2)$ & $2069(60.9)$ & 0.15 \\
\hline & No & $6891(37.8)$ & $1326(39.1)$ & \\
\hline \multirow[t]{2}{*}{ Use of dental check-up in the last 12 months } & Yes & $14,579(79.8)$ & $2463(72.6)$ & $<0.01$ \\
\hline & No & $3685(20.2)$ & $932(27.4)$ & \\
\hline
\end{tabular}


Table 2 Results of the multivariable logistic regression model with utilization of dental check-ups in the 12 months prior to the interview as the dependent variable. Odds ratios (OR) and 95\% confidence intervals [95\%-Cl] (German health update 2010 survey, $n=21,741$ )

\begin{tabular}{|c|c|c|c|c|}
\hline \multicolumn{2}{|l|}{ Independent variable } & \multicolumn{3}{|c|}{ Model 2} \\
\hline & & \multirow{2}{*}{$\begin{array}{l}\mathrm{OR} \\
0.71\end{array}$} & \multicolumn{2}{|c|}{$95 \%-\mathrm{Cl}$} \\
\hline Migration status (ref.: non-migrant) & migrant & & 0.65 & 0.77 \\
\hline Sex (ref.: male) & female & 1.88 & 1.76 & 2.00 \\
\hline \multirow[t]{6}{*}{ Age (ref.: 18-29 years) } & 30-39 years & 1.36 & 1.21 & 1.52 \\
\hline & $40-49$ years & 1.65 & 1.48 & 1.85 \\
\hline & $50-59$ years & 1.43 & 1.27 & 1.60 \\
\hline & $60-69$ years & 1.25 & 1.11 & 1.41 \\
\hline & 70-79 years & 1.15 & 1.01 & 1.31 \\
\hline & $80+$ years & 0.39 & 0.32 & 0.47 \\
\hline \multirow[t]{2}{*}{ Socioeconomic status (ref.: low) } & middle & 1.70 & 1.54 & 1.87 \\
\hline & high & 2.36 & 2.10 & 2.65 \\
\hline Type of health insurance (ref.: statutory) & private or other & 0.78 & 0.71 & 0.85 \\
\hline Living together with a partner/spouse (ref.: no) & yes & 1.41 & 1.31 & 1.51 \\
\hline Place of residence (ref.: East) & West Germany & 0.87 & 0.79 & 0.95 \\
\hline Urban residence (ref.: no) & yes & 0.94 & 0.87 & 1.01 \\
\hline
\end{tabular}

migrants than non-migrants. Even after adjusting for a variety of individual and structural factors, having a migrant background was still associated with an almost $30 \%$ lower chance of utilization. These findings are in line with studies from other countries [18-21] and suggest that additional factors associated with migrant background need to be considered when addressing differences in the utilization of dental prevention.

All of the covariates we included as potential confounders were significantly associated with the outcome, with the sole exception of living in an urban area. The associations identified were generally in line with findings from other studies on the utilization of dental services. Having a higher socioeconomic status was associated with an increased chance for utilizing dental prevention, which is consistent with results from previous research [27, 33]. The lower chance of utilization among adults with private insurance or other type of funding is likely to be related to differences in copayment and reimbursement agreements [34]. Being female and living with a partner (or being married) was also found to increase the chance of dental service utilization among adults in Denmark [21].

Utilization of health services by migrants can be limited due to a variety of potential barriers on the patient, provider and system level. On the patient level, culturally specific perceptions and beliefs of health and illness, low health literacy (including knowledge about the health system), limited language skills, perceptions and attitudes towards health services and personnel and low family or social support are important factors limiting the utilization of preventive care [35]. Since the sample included only adults with a high proficiency of the German language, language barriers can be excluded as a major influence in our sample. In addition, culturally specific health and illness beliefs may influence the utilization of preventive measures [35].

Some migrants have been reported to not using health services until they exhibit symptoms [36]. This means they probably do not perceive the necessity or benefits of prevention as strongly as non-migrants and cannot be reached to the same extent by existing preventive efforts. Low health literacy or a lack of information on the German health system may further reduce the chances of using preventive services. Studies have shown that one of the main risk factors for caries among migrant children in Germany is parents' lack of knowledge and awareness of the negative effects of sugar and sweet foods [37]. Migrant parents also tend to underestimate the benefits of prophylactic efforts and products (e.g. fluoride tablets) [16]. Although these studies surveyed parents on the oral health of their children, the findings probably may also be attributable to their perceptions of oral health in general. This, however, needs to be verified by future studies examining knowledge and beliefs of adults concerning their own oral health.

Acquisition of information on the structure of the German health system, available preventive services and financial aspects of healthcare can be problematic as well. A considerable barrier to accessing health care including measures of prevention is the cost of these services [9]. In Germany, dental check-ups once every 
6 months are exempt from co-payment. If this is unknown, anticipated cost may still be a considerable barrier.

Also communication problems can be a source of underutilization, despite high language proficiency. Different modes or patterns of communication may negatively influence the relationship between dentists and migrant patients and through this impede health service utilization. A study among parents in Germany found that, compared to German parents, Turkish parents reported receiving insufficient information more often, trusted their dentist less and felt more often that their dentist was trying to give them a guilty conscience if the children had poor dental hygiene [38].

Barriers on the provider and system level comprise, amongst others, a limited cultural sensitivity of health services, missing information on existing services, a largely biomedical understanding of health and negative perception of or attitudes towards migrant patient groups including discrimination [35]. While different barriers have been identified that migrants in Germany encounter in different sectors of the health care setting $[2,36,39]$, the relevant barriers responsible for the underutilization of dental check-ups yet need to be identified.

Some limitations of our study need to be considered. The sample is not representative for the general population of migrants in Germany. This is reflected in the fact that high proficiency of the German language was an inclusion criterion and in the fact that migrants were underrepresented in the sample [28]. This limits generalizability of our findings. Given the positive selection and the known effect of poor language proficiency, the observed differences between migrants and the majority population are likely underestimated. Another limitation is the categorization of the migration status. The term migrant comprises a very heterogeneous group with a large diversity in terms of religious beliefs, culturally specific perceptions, values, languages and length of stay. As these factors may also be associated with the utilization of preventive measures of dental care [40, 41], further research should examine how they are related to the lower utilization observed for migrants in Germany. This could inform the development of targeted interventions. Although we could not take these diversity factors into account, we were able to include not only migrants with a non-German nationality but, unlike other health research studies in Germany which use secondary data, to also consider Germans with a migrant background [2]. Around 7\% of the German adult population are estimated to have no landline telephone connection [42]. Due to the design of the 'German Health Update' survey, these individuals were not included in the sample. However, considering the low number of households that are mobile-only or without any phone, we consider the resulting bias to be small. Furthermore, official statistics show that the socioeconomic composition of the sample is very similar to that of the population in Germany [43].

\section{Conclusions}

The utilization of annual dental check-ups in Germany is lower among adult migrants than among non-migrants, even after taking into account several demographic, socioeconomic and contextual factors. These findings are in line with findings from other studies on the utilization of preventive dental care measures among migrant children as well as studies on other types of preventive services. Our findings highlight the necessity of culturally sensitive and targeted services in the dental care setting. This includes communication on the system level (in terms of providing information on existing services and structures) as well as on the provider level (in terms of patientprovider interaction), the design and delivery of services (in terms of patient approach, waiting times and opening hours) as well as patient education to enhance health literacy. Future studies, applying qualitative or mixed-method approaches, need to explore the relevant barriers which migrants encounter in preventive dental care.

\section{Abbreviations}

95\%-Cl: 95\%-confidence interval; KiGGS: German Health Interview and Examination survey for Children and Adolescents [Studie zur Gesundheit von Kindern und Jugendlichen in Deutschland]; OR: Odds ratio;

SES: Socioeconomic status

\section{Acknowledgements}

Not applicable.

\section{Funding}

The study was funded by means of own resources. The publication costs of this article were funded by the German Research Foundation/DFG and the Technische Universität Chemnitz in the funding programme Open Access Publishing.

\section{Availability of data and materials \\ The data that support the findings of this study are available from the Robert Koch Institute. Access to the data is provided by 'FG 21 - Epidemiologisches Datenzentrum/Biometrie' of the Robert Koch Institute upon application; see http://www.rki.de/DE/Content/Gesundheitsmonitoring/ Forschungsdatenzentrum/antraege_pdf/GEDA2010.pdf).}

\section{Authors' contributions}

FE and DW developed the concept and design of the study, performed the statistical analysis, interpreted the findings and drafted the manuscript. PB helped with the study design and data interpretation and critically revised the manuscript. All authors read and approved the final manuscript.

Competing interests

The authors declare that they have no competing interests.

Consent for publication

Not applicable. 


\section{Ethics approval and consent to participate}

We use secondary data from a national survey, collected by a scientific institution of the German Federal Ministry of Health. The survey received approval from the Federal Commissioner for Data Protection and Freedom of Information (BfDI), and fulfils all necessary requirements and guidelines of the Federal data protection act of the Federal Republic of Germany. As the survey was fully anonymous, voluntary and did not involve any experiments, no further ethical approval was necessary according to national standards for secondary data analyses in Germany [44]. Secondary data analyses are also exempted from ethical evaluation by the Ethics Commission of Chemnitz University of Technology. Administrative permission to access and use of the German Health Update 2010 survey data has been granted by the Robert Koch Institute.

\section{Publisher's Note}

Springer Nature remains neutral with regard to jurisdictional claims in published maps and institutional affiliations.

\section{Received: 3 November 2016 Accepted: 10 May 2017}

\section{Published online: 19 May 2017}

\section{References}

1. Federal Office for Migration and Refugees. Migration report 2015. Central conclusions. Nuremberg: Federal Office for Migration and Refugees; 2016.

2. Brzoska P, Ellert U, Kimil A, Razum O, Saß A-C, Salman R, et al. Reviewing the topic of migration and health as a new national health target for Germany. Int J Public Health. 2015;60:13-20.

3. Norredam M, Nielson SS, Krasnik A. Migrants' utilization of somatic healthcare services in Europe-a systematic review. Eur J Pub Health. 2009; 20(5):555-63.

4. Bozorgmehr K, Razum O. Effect of restricting access to health care on health expenditures among asylum-seekers and refugees: a quasi-experimental study in Germany, 1994-2013. PLoS ONE. 2015;10(7):e0131483.

5. Diaz E, Calderon-Larranaga A, Prado-Torres A, Poblador-Plou B, Gimeno-Feliu LA. How do immigrants use primary health care services? A register-based study in Norway. Eur J Pub Health. 2015;25(1):72-8.

6. Pitkin Derose K, Bahney BW, Lurie N, Escarce JJ. Review: immigrants and health care access, quality, and cost. Med Care Res Rev. 2009;66(4):355-408.

7. Norredam M, Krasnik A. Migrants' access to health services. In: Rechel B, Mladovsky P, Deville W, Rijks B, Petrova-Benedict R, McKee M, editors. Migration and health in the European Union. Birkshire: Open University Press; 2011. p. 67-78.

8. Brzoska P, Abdul-Rida C. Participation in cancer screening among female migrants and non-migrants in Germany. A cross-sectional study on the role of demographic and socioeconomic factors. Medicine. 2016;95(30):e4242.

9. Spallek J, Zeeb H, Razum O. Prevention among immigrants: the example of Germany. BMC Public Health. 2010;10(1):14.

10. Brzoska P, Voigtländer S, Spallek J, Razum O. Utilization and effectiveness of medical rehabilitation in foreign nationals residing in Germany. Eur J Epidemiol. 2010;25:651-60.

11. Aarabi G, Reißmann D, Heydecke G, Farhan D, Kofahl C. Die Mundgesundheit von Menschen mit Migrationshintergrund in Deutschland - eine kritische Betrachtung [Oral health of people with migration background in Germany - a critical evaluation]. Deutsche Zahnarztliche Zeitschrift. 2013;68(5):280-7.

12. Bissar AR, Oikonomou C, Koch MJ, Schulte AG. Dental health, received care, and treatment needs in 11- to 13-year-old children with immigrant background in Heidelberg, Germany. Int J Paediatr Dent. 2007;17(5):364-70.

13. Cvikl B, Haubenberger-Praml G, Drabo P, Hagmann M, Gruber R, Moritz A, et al. Migration background is associated with caries in Viennese school children, even if parents have received a higher education. BMC Oral Health. 2014;14(1):661.

14. Stecksén-Blicks C, Hasslöf P, Kieri C, Widman K. Caries and background factors in Swedish 4-year-old children with special reference to immigrant status. Acta Odontol Scand. 2014;72(8):852-8.

15. Knopf H, Rieck A, Schenk L. Mundhygiene: Daten des KiGGS zum Kariespräventiven Verhalten [KIGGS data on caries preventative behavior]. Bundesgesundheitsbl Gesundheitsforsch Gesundheitsschutz. 2008:51(11): 1314-20.

16. Schenk L, Knopf H. Mundgesundheitsverhalten von Kindern und Jugendlichen in Deutschland [Oral health behaviour of children and adolescents in Germany. First results of the German health interview and examination survey for children and adolescents (KiGGS)].

Bundesgesundheitsbl Gesundheitsforsch Gesundheitsschutz. 2007;50(5-6): 653-8.

17. Giannobile WW, Braun TM, Caplis AK, Doucette-Stamm L, Duff GW, Kornman KS. Patient stratification for preventive care in dentistry. J Dent Res. 2013; 92(8):694-701.

18. Carrasco-Garrido P, De Miguel AG, Barrera VH, Jimenez-Garcia R. Health profiles, lifestyles and use of health resources by the immigrant population resident in Spain. Cent Eur J Public Health. 2007;17(5):503-7.

19. Bedos C, Brodeur JM, Benigeri M, Olivier M. Utilization of preventive dental services by recent immigrants in Quebec. Can J Public Health. 2003;95(3): 219-23.

20. Hjern A, Grindefjord M. Dental health and access to dental care for ethnic minorities in Sweden. Ethn Health. 2000:5(1):23-32.

21. Christensen LB, Petersen PE, Steding-Jessen M. Consumption of dental services among adults in Denmark 1994-2003. Eur J Oral Sci. 2007;115(3): 174-9.

22. Kühnisch J, Senkel H, Heinrich-Weltzien R. Vergleichende Untersuchung zur Zahngesundheit von deutschen und ausländischen 8- bis 10-Jährigen des westfälischen Ennepe-Ruhr-Kreises [Comparative study on the dental health of German and immigrant 8- to 10-years olds in the Westphalian EnnepeRuhr District]. Gesundheitswesen. 2003;65(2):96-101.

23. van Steenkiste M, Becher A, Banschbach R, Gaa S, Kreckel S, Pocanschi C. Prävalenz von Karies, Fissurenversiegelungen und Füllungsmaterial bei deutschen Kindern und Kindern von Migranten [Prevalence of caries, fissure sealants and filling materials among German children and children of migrants]. Gesundheitswesen. 2004;66(11):754-8.

24. Brand T, Kleer D, Samkange-Zeeb F, Zeeb H. Prävention bei Menschen mit Migrationshintergrund [Prevention among migrants. Participation, migrant sensitive strategies and programme characteristics]. Bundesgesundheitsbl Gesundheitsforsch Gesundheitsschutz. 2015;58(6):584-92.

25. Chattopadhyay A, Kumar JV, Green EL. The New York State minority health survey: determinants of oral health care utilization. J Public Health Dent. 2003;63(3):158-65

26. Sakki TK, Knuuttila ML, Anttila SS. Lifestyle, gender and occupational status as determinants of dental health behavior. J Clin Periodontol. 1998;25(7): 566-70.

27. Listl S. Income-related inequalities in dental service utilization by Europeans aged 50+. J Dent Res. 2011;90(6):717-23.

28. Lange C, Jentsch F, Allen J, Hoebel J, Kratz AL, der Lippe E, et al. Data resource profile: German health update (GEDA) - the health interview survey for adults in Germany. Int J Epidemiol. 2015;442-50.

29. Robert Koch-Institut. Gesundheit in Deutschland aktuell 2010. Public use file GEDA 2010. Berlin: Robert Koch-Institut; 2012.

30. Lampert T, Kroll LE, Müters S, Stolzenberg H. Messung des sozioökonomischen Status in der Studie 'Gesundheit in Deutschland aktuell' (GEDA) [Measurement of the socioeconomic status within the German health update 2009 (GEDA)]. Bundesgesundheitsbl Gesundheitsforsch Gesundheitsschutz. 2013;56(1):131-43.

31. Tabachnick BG, Fidell LS. Using multivariate statistics. Boston: Pearson; 2010.

32. StataCorp. Stata statistical software: release 13. College Station: StataCorp LP 2013

33. Keller A, Baune B. Impact of social factors on health status and help seeking behavior among migrants and Germans. J Public Health. 2005;13(1):22-9.

34. Riesberg A, Wörz M. Quality in and equality of access to healthcare services - country report for Germany. European Commission: Brussels; 2008.

35. Scheppers E, Van Dongen E, Dekker J, Geertzen J, Dekker J. Potential barriers to the use of health services among ethnic minorities: a review. Fam Pract. 2006;23(3):325-48

36. Yilmaz-Aslan Y, Brzoska P, Bluhm M, Aslan A, Razum O. Illness perceptions in Turkish migrants with diabetes: a qualitative study. Chronic IIIn. 2014;10(2): $107-21$.

37. Yüksel S. Karieserfahrung bei Kleinkindern - Korrelation zu verschiedenen Ernährungs- und Prophylaxeparametern [Experiences of caries in infants correlation with several nutritional and prophylaxis parameters]. Dissertation. Marburg: Universität Marburg; 2010

38. van Steenkiste M. Zugang zu zahnärztlichen Leistungen und Einstellung zum Zahnarzt bei deutschen und türkischen Eltern [Access to oral care and attitudes to the dentist by German and Turkish parents]. Gesundheitswesen. 2004;66(02):93-101. 
39. Berens EM, Yilmaz-Aslan Y, Spallek J, Razum O. Determinants of mammography screening participation among Turkish immigrant women in Germany - a qualitative study reflecting key informants' and women's perspectives. Eur J Cancer Care. 2015

40. Lebrun LA. Effects of length of stay and language proficiency on health care experiences among immigrants in Canada and the United States. Soc Sci Med. 2012;74(7):1062-72.

41. Gao XL, McGrath C. A review on the oral health impacts of acculturation. J Immigr Minor Health. 2011;13(2):202-13.

42. Busse $B$, Fuchs $M$. The components of landline telephone survey coverage bias. The relative importance of no-phone and mobile-only populations. Qual Quant. 2012;46(4):1209-25.

43. Statistisches Bundesamt. Bevölkerung und Erwerbstätigkeit. Bevölkerung mit Migrationshintergrund. Ergebnisse des Mikrozensus 2010 (Fachserie 1 Reihe 2.2) [Population and employment. Population with a migration background. Findings from the Microcensus 2010]. Wiesbaden: Statistisches Bundesamt; 2011.

44. Arbeitsgruppen 'Erhebung und Nutzung von Sekundärdaten' und 'Epidemiologische Methoden' der DGSMP/DGEpi/GMDS: GPS - Gute Praxis Sekundärdatenanalyse: Revision nach grundlegender Überarbeitung [Good practice of secondary data analysis, first revision]. Gesundheitswesen. 2008; 70:54-60.

\section{Submit your next manuscript to BioMed Central} and we will help you at every step:

- We accept pre-submission inquiries

- Our selector tool helps you to find the most relevant journal

- We provide round the clock customer support

- Convenient online submission

- Thorough peer review

- Inclusion in PubMed and all major indexing services

- Maximum visibility for your research

Submit your manuscript at www.biomedcentral.com/submit 